\title{
Bending the Foundation Beam on Elastic Base by Two Reaction Coefficient of Winkler's Subgrade
}

\author{
Mirko Balabušić1, Boris Folić ${ }^{2}$, Slobodan Ćorić ${ }^{3}$ \\ ${ }^{1}$ Independent Designer of Structure, Herceg Novi, Montenegro \\ ${ }^{2}$ Innovation Center, Faculty of Mechanical Engineering, University of Belgrade, Belgrade, Serbia \\ ${ }^{3}$ Faculty of Mining and Geology, University of Belgrade, Belgrade, Serbia \\ Email: balabusicm@gmail.com
}

How to cite this paper: Balabušić, M., Folić, B. and Corić, S. (2019) Bending the Foundation Beam on Elastic Base by Two Reaction Coefficient of Winkler's Subgrade. Open Journal of Civil Engineering, 9, 123-134. https://doi.org/10.4236/ojce.2019.92009

Received: February 26, 2019

Accepted: June 2, 2019

Published: June 5, 2019

Copyright $\odot 2019$ by author(s) and Scientific Research Publishing Inc. This work is licensed under the Creative Commons Attribution International License (CC BY 4.0).

http://creativecommons.org/licenses/by/4.0/

(c) (i) Open Access

\begin{abstract}
A new method for analysis of counter beams is presented in the paper. The analysis has taken into account their stiffness EI, Winkler's space with modulus of subgrade reaction $k$ and equality deformities of the foundation beam with the ground. The solution is found by using the numerical analysis of the Winkler's model, with variation of different moduli of the subgrade reaction $k_{2}$ outside the force zone $r$, while under the force $P$ exists the modulus of the subgrade reaction $k$, up to the definition of minimum bending moments. The exponential function $k_{2}(r)$, as the geometric position of the minimum moments is approximately assumed. From the potential energy conditions of the reciprocity of displacement and reaction, the width of the zone $r$ and the modulus of the subgrade reaction $k_{2}$ are explicitly determined, introducing in the calculation initial and calculation soil displacement $w_{s i}$ successively. At the end of the paper, it presented numerical example in which the influence of $k$ and $k_{2}$ values on bending moments of the counter beam is analyzed. The essential idea of this paper is to decrease the quantity of the reinforcement in the foundations, beams, i.e. to obtain a cost-efficient foundation construction.
\end{abstract}

\section{Keywords}

Foundation Beam, Winkler's Model, Coefficient of Subgrade Reaction

Modulus $k$ and $k_{2}$, Zone $r$ under the Force $P$, Soil Displacement $w_{s i}$

\section{Introduction}

When calculating a beam on a continuous deformable base, it is important to provide a modeling of the foundation beam base as realistic as possible, i.e. its 
approximation with the actual properties of soil beneath the foundations. Yet, the calculation methods should be kept simplified so that they could be widely implemented in practical applications.

Beam on elastic foundation has been analysed, most usually, based on the Winkler's model in which the soil is replaced by a bed of elastic springs. The compressive resistance of soil against the beam deflection is quantified in terms of spring constant $k$ [force/length ${ }^{2} /$ length], which is a frequent occurrence in the Euler-Bernoulli beam theory. Shear deformations are neglected and plane cross-section is assumed to remain plane and normal to the longitudinal axis deformation. Many researchers [1] [2] [3] [4] [5] have investigated the modulus of subgrade reaction and found that the geometry, the foundation dimensions and soil layering below the foundation structure are the most important parameters to define the value of this modulus. In the Winkler foundation model, the soil reactive pressure at any arbitrary point $x$ is proportional to the deflection and can be expressed as,

$$
q(x)=k \cdot w(x)
$$

where $k$ is the Winkler's coefficient of ground reaction at point $x$. Winkler foundation is a single parameter model, $k$ is used to describe the soil reaction.

The subgrade reaction modulus $k$ is dependent on some parameters like soil type, size and shape of foundations, depth and stress level. The foundation represented by the Winkler model [6] cannot sustain shear stress, and hence a discontinuity of adjacent spring displacement can occur. A different model may result in significant inaccuracies in the evaluated structural response. In order to overcome this problem, many researches have introduced a different mechanical model [7]-[14]. Among them is the class of two parameters foundation. The second parameter introduced the interaction between adjacent springs, in addition to the first parameter from the ordinary Winkler's model [15]. This procedure is proposed in [13] for homogenous elastic semi space.

In the [13] the elastic base is represented with a layer having thickness $H$, exposed to pressure, lying on top on an infinitely stiff horizontal base. One dimension of the compressed layer is large, and the load invariable in this direction; the supporting conditions and values of the elastic characteristic are constant, too. An in-plane stress and strain state is considered. The proposed model of soil has two soil characteristics, $k$ (characterising displacement of the elastic base under pressure) and $t$ (and describing behaviour of the subgrade during sliding and base "distribution properties"). Pasternak proposed that both soil characteristics ( $k$ and $t)$ are named the subgrade coefficients, i.e. the model of soil of two subgrade coefficients (as cited in [9]).

In [16] a closed-form analytical solution of the problem of bending of a beam on elastic foundation is proposed. The solution based on the total potential energy functional. In order to eliminated the bearing soil reaction as a variable in the problem solution of beam on elastic foundation, the simplified continuum 
approach, with a numerical research, is presented in [17]. Study the behaviour of a math foundation on subsoil from the plate theory taking into account the soil-structure interaction, and several model have been described, presented in [18]. Very important work related to subgrade reaction and analysis of beams on elastic foundation is [4] [5] [19].

The equations available for estimating the soil spring constant $k$ are mostly developed empirically [5], which is limitation of Winkler's model. In some instances, plate-load test are used to estimate $k$, but that estimations are not free from errors because the results depend on size, thickness and stiffness of the plate.

Two-parameter foundation models provide the displacement continuity of the soli medium by adding of a second spring which interacts with the first spring of the Winkler's model. Displacement continuity is provided for by the introduction of a virtual shear layer which integrates the vertical spring elements and the second foundation parameter $k_{2}$, is the shear modulus $G$ of the shear layer [16] [17]. The soil reaction $q(x)$ for two parameter foundation model is given in general by:

$$
q_{s}(x)=k_{1} w(x)-k_{2} \mathrm{~d}^{2} w(x) / \mathrm{d} x^{2}
$$

where $k_{1}$ and $k_{2}$ are two foundation parameters.

In the paper will be demonstrated that in a case of $k$ and $k_{2}$ model, bending moments in the counter beam are smaller than in a case of a $k$ model. The change of $k$ values does not significantly affect this difference.

\section{Theoretical Bases}

\subsection{Bernoulli Beam Theory}

The main assumption of Bernoulli beam theory is that cross-sectional rotations are the same as the rotations of the beam centroidal line. The Bernoulli beam element can be obtained by defining the total potential energy and applying the variational principle to it.

- Ground as linearly deformable described by Winkler's model.

- Ground is inhomogeneous and acting non-linearly under load

In all solutions, it is referred to the basic differential equation for Bernoulli beam resting on Winkler soil model [11] of the elastic beam, where soil replaced with an elastic spring [7] and [10] that displacements of points on the beam axis and the corresponding soil displacements are equal.

$$
E I\left(\mathrm{~d}^{4} w / \mathrm{d} x^{4}\right)=-[q(x)-p(x)] B
$$

The dependence between $q(x)$ and soil displacement $w(x)$ of basic ground surface is defined according to one of proposed models.

\subsection{Coefficient of Subgrade Modulus Reaction, $K$}

Winkler proposed a model that assumes the soil stiffness that is considered as 
the ratio between the contact pressures $(\Delta \sigma)$ and $(\Delta \delta)$ is linear, and it can be given by the coefficient of subgrade reaction $K$. It has units of force per unit volume $\left(\mathrm{MN} / \mathrm{m}^{3}\right)$.

$$
K=\Delta \sigma / \Delta \delta
$$

This theory simulates the soil behavior as a group of independent springs, governed by the linear-elastic model (Figure 1). The coefficient of subgrade reaction which is spring stiffness is the initial slope of the curve until the limit pressure (4).

The subgrade modulus reaction $k$ depends to the size of the load $q(x)$, shape and size of loaded area, type and compaction of the ground.

The recommendation is that the coefficient $k$ is to be determined on the previously calculated settlement of the foundation [20].

On the basis of theoretical and experimental investigations of various soil types, [4] recommended the numerical values of the soil reaction modulus, ranging from $1000\left(\mathrm{kN} / \mathrm{m}^{3}\right)$ to $100,000\left(\mathrm{kN} / \mathrm{m}^{3}\right)$ depending on the type and compaction of the ground.

He showed that the change of $k$ for $\pm 50 \%$ causes only minor changes of stress in the basic beam (17).

\section{Modeling}

\section{Influence on Bending Moments of Two Parameters $k$ and $k_{2}$}

A more accurate calculation of the actual distribution between the basic beam and ground is carried out for a different subgrade modulus.

According to the definition of pressure, the zones under the force $P$, where the construction makes compaction of the ground, can be considered as the zone of Modulus of subgrade reaction $k$. shown in Figure 2. Outside of these zones, where the ground causes the deformation of the structure, acts a reduced Modulus of subgrade reaction $k_{2}$, which is required to be determined by numerical analysis.

The differential Equation (3) of the Winkler space now takes the form (5), (after [7] [10] and [11]),

$$
E I \mathrm{~d}^{4} w / \mathrm{d} x^{4}=-\left[w(x)\left(\left(\left(l_{p}-r\right) / l_{p}\right) \times k_{2}+\left(r / l_{p}\right) \times k\right)-p(x)\right] B .
$$

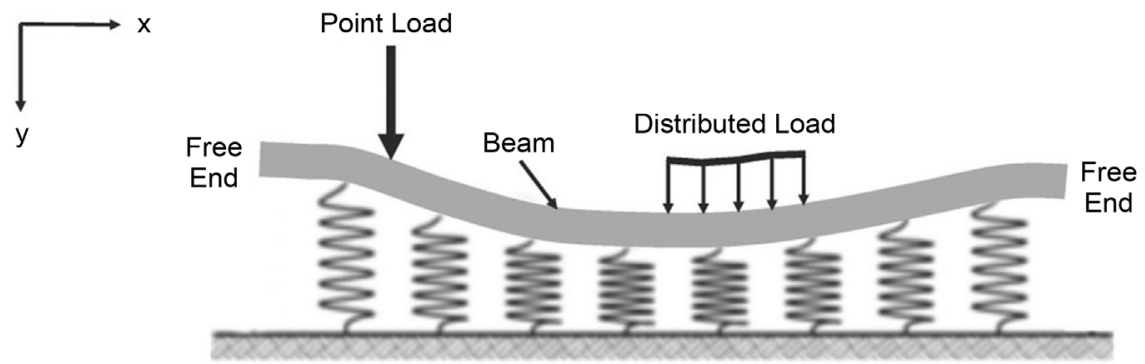

Figure 1. Beam on elastic foundation-group of elastic springs. 


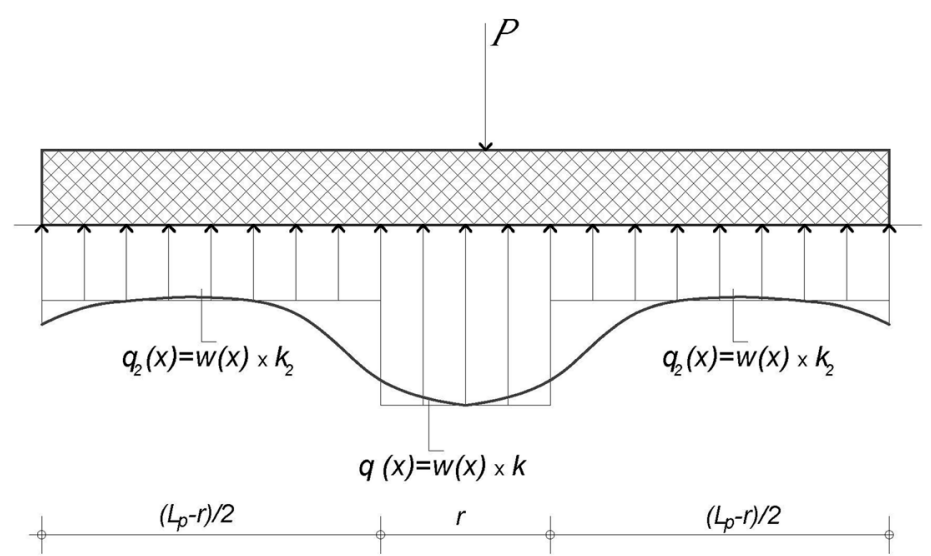

Figure 2. Reactive load with subgrade reaction modulus $k$ and $k_{2}$, (after [7] [10] [11]).

where $l_{p}$ is length of the basic beam, while $r$ is the ground corresponding resistance zone below the force $P$.

For $r=0, k_{2}$ acting on the whole basic beam.

For $r=l_{p}, k$ acting on the whole basic beam.

\section{Analytical Solutions}

\subsection{Condition of the Minimum}

From the conditions of equality of the first derivative (6) with zero in the center of the beam, below the force $P$, the numerical analysis contains the minimum of the moments for variables $\left(x, r, k_{2}\right)$. Numerical example (Figures 3-5)

$$
\begin{gathered}
\mathrm{d} M_{i} / \mathrm{d}\left(x, r, k_{2}\right)=0 \\
E I \mathrm{~d}^{3} w(x) /\left(\mathrm{d}^{3}\left(x, r, k_{2}\right)\right)=0
\end{gathered}
$$

\subsection{Exponential Equation of $k_{2}(r)$ as Approximate Numerical \& Graphical Solution}

From presented diagrams of bending moments (Figures 3-5), for $k_{2}=k / 2 ; k / 5$ and $k / 10$, the geometric minimum position $k_{2}(r)$ is obtained as the exponential function (7) respectively for $r=4 \mathrm{~m}, 3 \mathrm{~m}$ and $2 \mathrm{~m}$.

$$
k_{2}(r)=\mathrm{e}^{a r^{2}+b r+c}=\mathrm{e}^{0.1116 r^{2}+0.1353 r+\ln (k / 20.87)}
$$

\subsection{Principle of Virtual Work}

The principle of virtual work described the equilibrium of beam-soil system. Applying the theorem on the reciprocity of displacement and reaction [22], the following equation is obtained (8).

$$
\begin{gathered}
{\left[k_{2} \times \int_{0}^{l_{p}-r} w(x) \mathrm{d} x+k \times \int_{l_{p}-r}^{r} w(x) \mathrm{d} x\right] \times B=P .} \\
{\left[k_{2} \times\left. A(x)\right|_{0} ^{l_{p}-r}+k \times\left. A(x)\right|_{l_{p}-r} ^{r}\right] \times B=P .}
\end{gathered}
$$




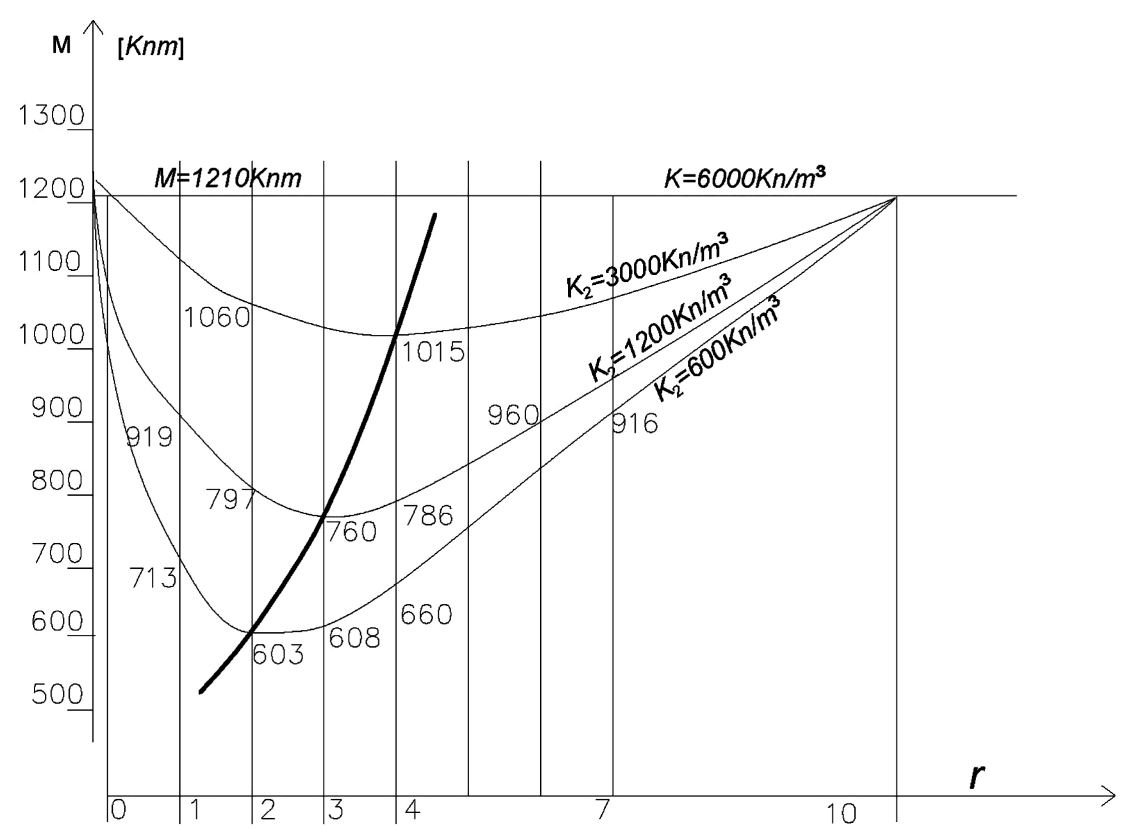

Figure 3. Moments in foundation beam for $k=6000 .\left(\mathrm{kN} / \mathrm{m}^{3}\right), k_{2}=k / 2 ; k / 5 ; k / 10$, (after [21]).

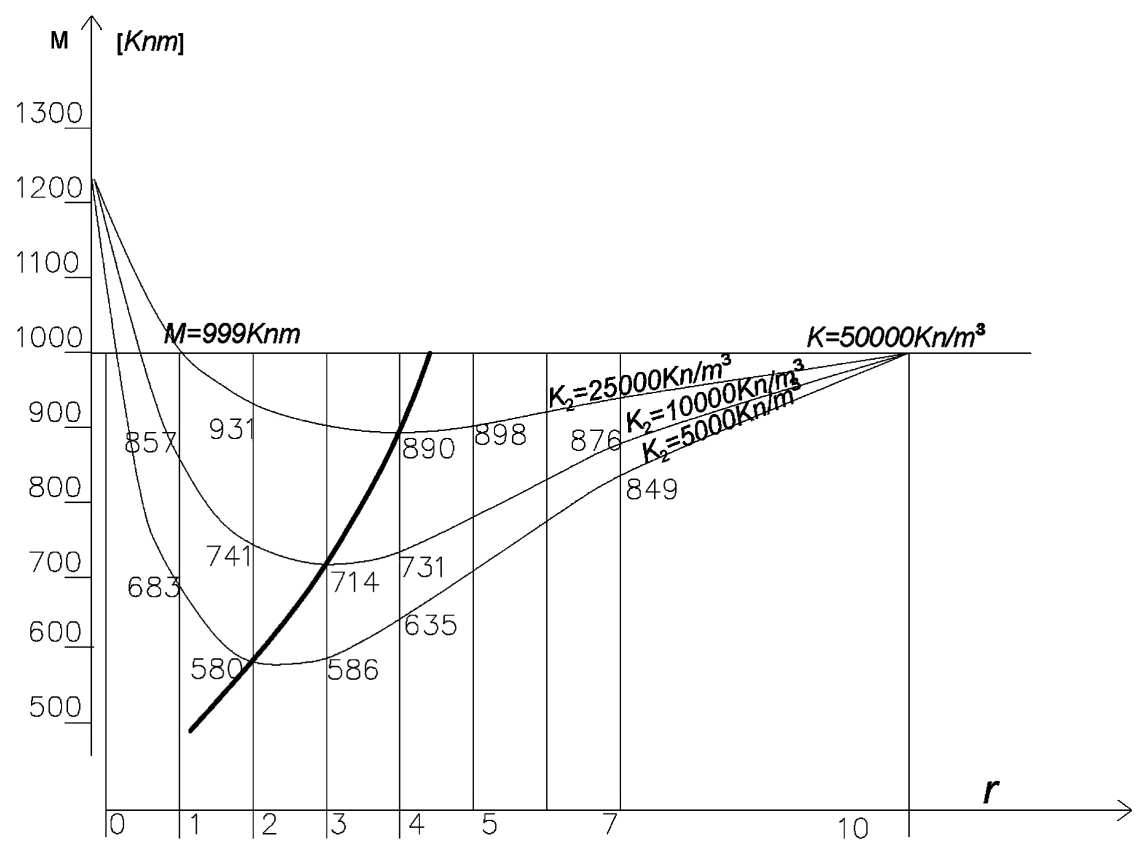

Figure 4. Moments in foundation beam for $k=50,000 .\left(\mathrm{kN} / \mathrm{m}^{3}\right), k_{2}=k / 2 ; k / 5 ; k / 10$, (after [21]).

It is accepted that the soil displacement has a mean value from the calculating $\max u_{i}$ and $\min u_{i}$

$$
w_{s i}=\left(\max u_{i}+\min u_{i}\right) / 2,\left.A(x)\right|_{l_{p}-r} ^{r}=r \times w_{s i}^{r} .
$$

If it is accepted the initial soil displacement 


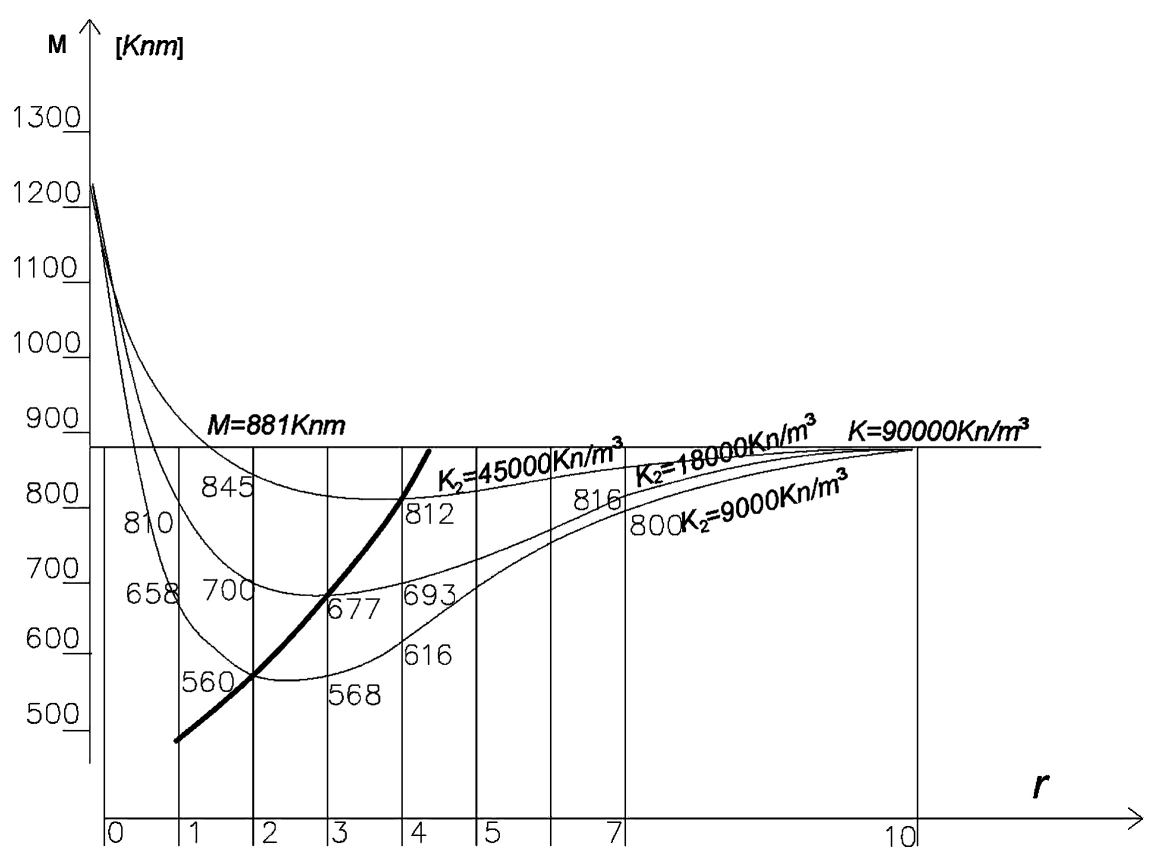

Figure 5. Moments in foundation beam for $k=90,000 .\left(\mathrm{kN} / \mathrm{m}^{3}\right), k_{2}=k / 2 ; k / 5 ; k / 10$ (after [21]).

$$
w_{s o}=\left(1-v^{2}\right) / k \times I \times p(x)
$$

In accordance with Businesque solution for the soil displacement of a homogeneous, isotropic, linearly elastic half-space loaded with concentrated force $\mathrm{P}$ (Figure 2), where $v$ Poisson's coefficient $=(0.2-0.4)$ for the sand, i.e. $=0.5$ for clay.

I-the influential factor for the vertical soil displacement of the foundation, for the relation $I / B=10, I=2.246$ [23].

A somewhat greater initial soil displacement is adopted, since higher calculation $u_{i}$ of soil displacement are expected due to the reduction of the modulus of compressibility $\left(k_{2}\right)$ on the part of the beam core carrier, where $k_{2}<k$.

Finally, Equation (8) has the simplified from (11) as,

$$
k_{2} \times\left(l_{p}-r\right) \times w_{s i}^{l_{p}-r}+k \times r \times w_{s i}^{r}=P
$$

\section{Numerical Example}

The characteristic for this numerical example is that it is about a basic counter beam with an adopted width of $B=1.0(\mathrm{~m})$ and height $D=1.0(\mathrm{~m})$, loaded with force $P=1000(\mathrm{kN})$ in the middle, which lies on the elastic half-space (Figure 2).

In this example, three ground coefficients were analyzed: $k=6000\left(\mathrm{kN} / \mathrm{m}^{3}\right), k=$ $50,000\left(\mathrm{kN} / \mathrm{m}^{3}\right), k=90,000\left(\mathrm{kN} / \mathrm{m}^{3}\right)$ and corresponding impacts (bending moments) were shown on the foundation beam (Figure 6).

The numerical analysis of the Winkler's space on the basic beam for subgrade 


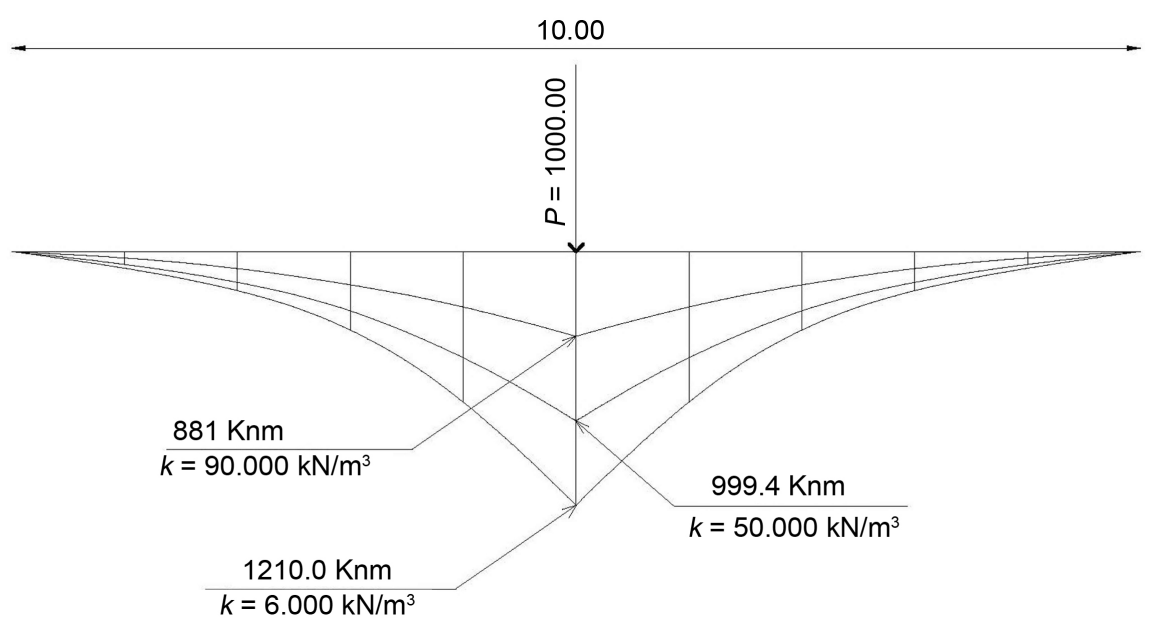

Figure 6. Winkler's space-bending moments with different $k$ modulus on the basic beam, (modified from [21]).

reaction Modulus $k=6000\left(\mathrm{kN} / \mathrm{m}^{3}\right), k=50,000\left(\mathrm{kN} / \mathrm{m}^{3}\right)$ and $k=90,000$ $\left(\mathrm{kN} / \mathrm{m}^{3}\right)$, from Equation (11), where the subgrade reaction modulus $k_{2}$ are obtained as is shown in Figures 7-9.

\subsection{Solving Equation (12)}

From the above two conditions (7) and (8), the numerical analysis from several steps gives explicitly the variable constants $\left(r, k_{2}\right)$.

It is necessary to solve Equation (12) in accordance with conditions (7) and (11).

The solution is found by American math program Wolfram Alfa:

$$
0.1116 r^{2}+0.1353 r+\ln (k / 20.48)=\ln \left(P-k \times w_{s i}^{r} \times r\right)-\ln \left(l_{p}-r\right) \times w_{s i}^{l_{p}-r}
$$

\subsection{Numerical Results}

1) $k=6000\left(\mathrm{kN} / \mathrm{m}^{3}\right) ; P=1000(\mathrm{kN}) ; w_{s i}^{l_{p}-r}=0.0506(\mathrm{~m}) ; w_{s i}^{r}=0.0514(\mathrm{~m})$; $I_{p}=10(\mathrm{~m}) ; r=2.32(\mathrm{~m}) ; k_{2}=732\left(\mathrm{kN} / \mathrm{m}^{3}\right)>k / 10$

2) $k=50,000\left(\mathrm{kN} / \mathrm{m}^{3}\right) ; P=1000(\mathrm{kN}) ; w_{s i}^{l_{p}-r}=0.0046(\mathrm{~m}) ; w_{s i}^{r}=0.052(\mathrm{~m})$; $I_{p}=10(\mathrm{~m}) ; r=2.78(\mathrm{~m}) ; k_{2}=8390\left(\mathrm{kN} / \mathrm{m}^{3}\right)<k / 5$.

3) $k=90,000\left(\mathrm{kN} / \mathrm{m}^{3}\right) ; P=1000(\mathrm{kN}) ; w_{s i}^{l_{p}-r}=0.0016(\mathrm{~m}) ; w_{s i}^{r}=0.0023(\mathrm{~m})$; $I_{p}=10(\mathrm{~m}) ; r=3.48(\mathrm{~m}) ; k_{2}=27,184\left(\mathrm{kN} / \mathrm{m}^{3}\right)>k / 5$.

When analyzing a beam on the Winkler's base with ground modulus reaction $k$ and $k_{2}$, which are discontinuously changed along the length of the underlying beam, the obtained results differ successively by $88 \%, 45 \%$ and $19 \%$ percentage respectively (Figure 10).

\section{Summary and Conclusions}

A new method for analysis of the counter beam is presented hereby. The analysis is based on variational principles of mechanics and an approximate numerical-graphical solution, in which a rational soil-displacement field, influence zone $r$ 

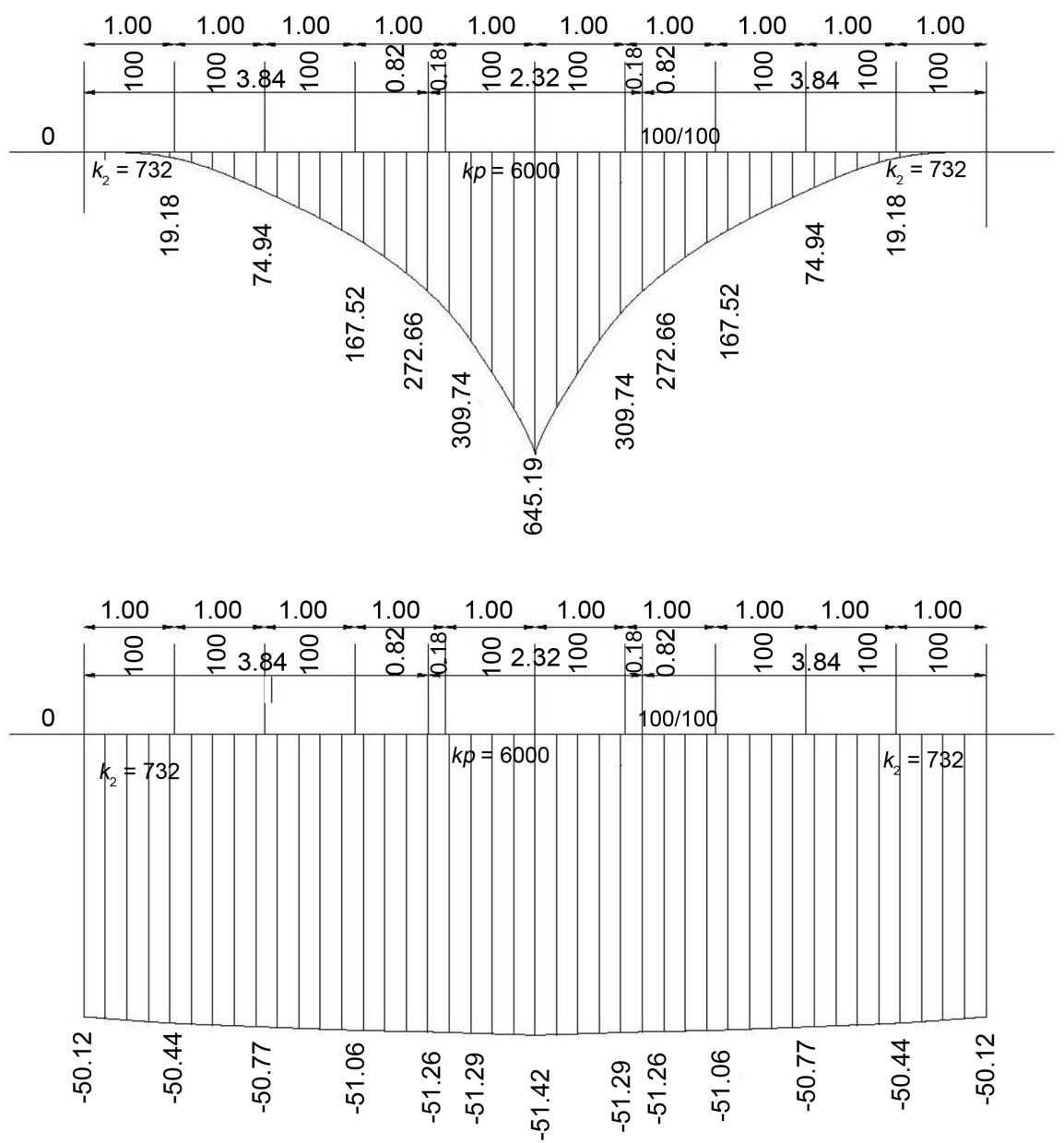

Figure 7. Moments and soil displacement $\left(10^{-3}(\mathrm{~m})\right)$, of counter beam for $k=6000$ $\left(\mathrm{kN} / \mathrm{m}^{3}\right)$, for $k_{2}=732\left(\mathrm{kN} / \mathrm{m}^{3}\right), r=2.32(\mathrm{~m})$, (reprinted from [21]).

and subgrade reaction modulus $k_{2}$ are obtained. In accordance with the analysis carried out for the basic Winkler's model of the foundation beam, it is noted that for the different values of the subgrade reaction modulus $k$, uniformly disposed under the beam, its change does not significantly affect the value of results.

It is noticed that if the coefficient of the ground reaction is applied to a foundation beam with different values $k_{2}<k$, the subgrade reaction modulus has a value $k$, in the compressed zone under the effect of force. Simultaneously, in zones outside the force (wall, column) the $k_{2}$ modulus is adopted. At low values of $k$, the effects obtained are more than two times lower than the effects in the basic Winkler's model, as shown in Figure 10. What is accepted than the subgrade reaction modulus $k_{2}$ is the geometric position minimum of the moments as an approximate exponential function (7). The savings in the reinforcement of the foundation beam can be achieved by reducing the calculated amount of reinforcement obtained by the Tower program by the factor $F_{a}<2.00$, which depends on the size of subgrade reaction modulus $k$. The lower the subgrade reaction modulus $k$, the large the factor $F_{a}$. The proposed model can be analogously 

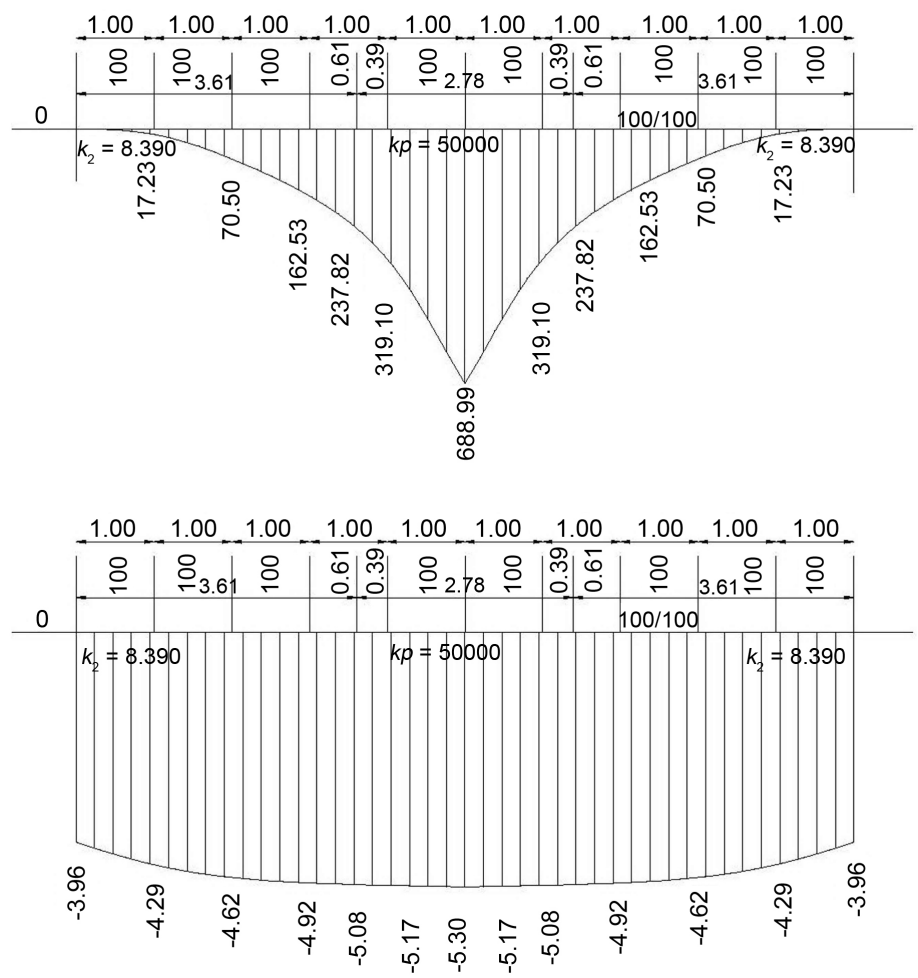

Figure 8. Moments and soil displacement $\left(10^{-3}(\mathrm{~m})\right)$, of counter beam for $k=50,000\left(\mathrm{kN} / \mathrm{m}^{3}\right)$, for $k_{2}=8390\left(\mathrm{kN} / \mathrm{m}^{3}\right), r=2.78(\mathrm{~m})$, (reprinted from [21]).
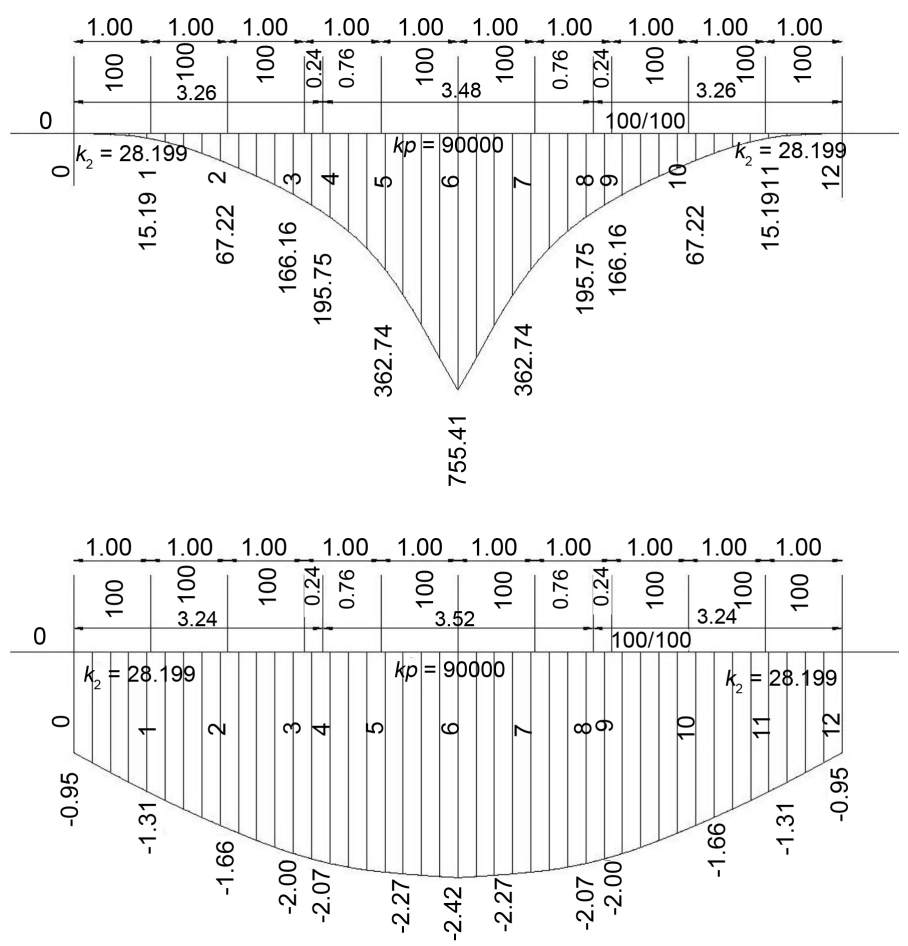

Figure 9. Moments and soil displacement $\left(10^{-3}(\mathrm{~m})\right)$, of counter beam for $k=90,000\left(\mathrm{kN} / \mathrm{m}^{3}\right)$, for $k_{2}=27,184\left(\mathrm{kN} / \mathrm{m}^{3}\right), r=3.48(\mathrm{~m})$, (reprinted from [21]). 


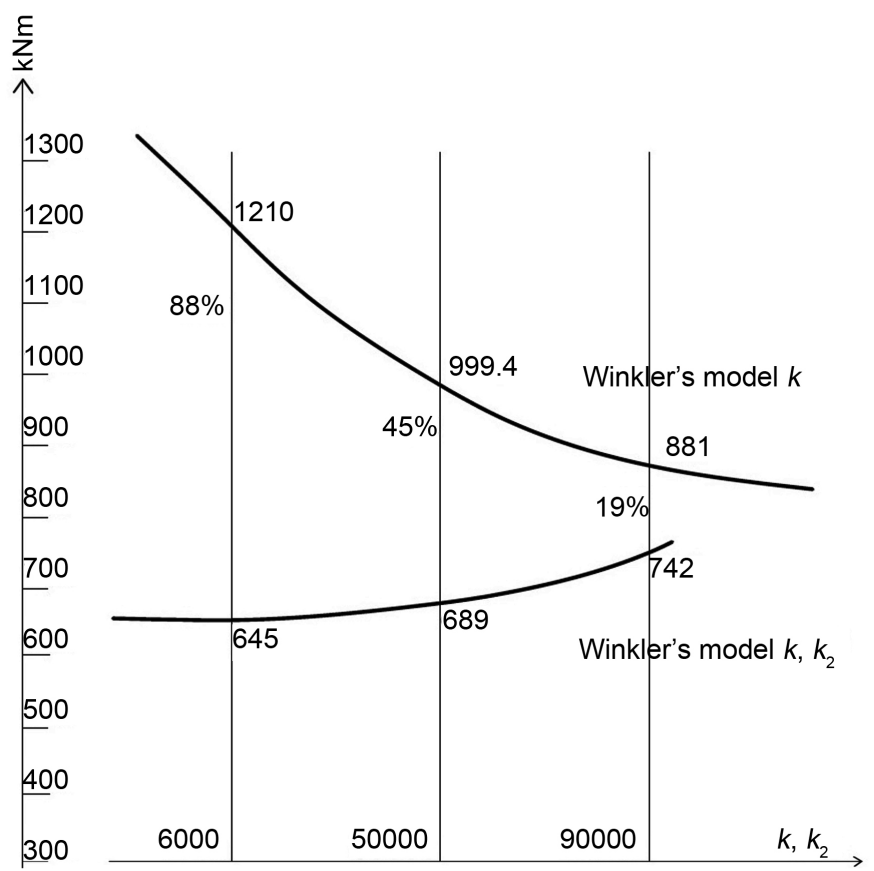

Figure 10. Comparison of Winkler's $k$ and $k, k_{2}$ model.

applied to the foundation counter slabs.

\section{Acknowledgements}

The authors wish to appreciate the significance help Rajko Radulovic const. engineer from Public Coastal Management, Budva, Montenegro for calculation of many examples and his great cooperation, during the completion of this research.

\section{Conflicts of Interest}

The authors declare no conflicts of interest regarding the publication of this paper.

\section{References}

[1] Abolmaali, A. and Kararam, A. (2013) Nonlinear Finite-Element Modeling Analysis of Soil-Pipe Interaction. International Journal of Geomechanics, 13, 197-204. https://doi.org/10.1061/(ASCE)GM.1943-5622.0000196

[2] Daloglu, A.T. and Vallabhan, C.V.G. (2000) Values of k for Slab on a Winkler Foundation. Journal of Geotechnical and Geoenvironmental Engineering, 126, 463-471. https://doi.org/10.1061/(ASCE)1090-0241(2000)126:5(463)

[3] Horvat, J.S. and Colasanti, R.J. (2011) Practical Subgrade Model for Improved-Soil-Structure Interaction Analysis: Model Development. International Journal of Geomechanics, 11, 59-64. https://doi.org/10.1061/(ASCE)GM.1943-5622.0000070

[4] Terzagi, K. (1955) Evaluation of Coefficients of Subgrade Reaction. Geotechnique, 5, 41-50. https://doi.org/10.1680/geot.1955.5.4.297 
[5] Vesić, A. (1961) Bending of Beams Resting on Isotropic Elastic Solid. Journal of the Engineering Mechanics Division, 87, 35-53.

[6] Winkler, E. (1867) Die Lehre von Elastizitat und Festigkeit (on Elasticity and Fixity). Dominicus, Prague.

[7] Bowels, J.E. (1988) Foundations Analysis and Design. McGraw-Hill, New York.

[8] Ćorić, S. (2008) Geostatic Calculation. Faculty of Mining and Geology, Belgrade. (In Serbian)

[9] Горбунов Посадов, М.И. and Маликова, Т.А. (1973) Расчет конструкций на упругом основании. Москва строиздат.

[10] Hetenyi, M. (1946) Beams on Elastic Foundation: Theory with Applications in the Fields of Civi; and Mechanical Engineering. University of Michigan Press, Ann Arbor.

[11] Nonveiller, E. (1981) Soil Mechanic and Foundation Engineering. School Book, Zagreb.

[12] Stevanović, S. (1999) Foundation of Civil Engineering Structures. Book 1, FCE, Belgrade.

[13] Власов, В.3. and Леонтъев, Н.Н. (1960) Балки, плиты и оболочки на упругом основании. Государственное издательство физико-математической литературы, Москва.

[14] Hansen, J.B. (1961) A General Formula for Bearing Capacity. Bulletin No. 11, Danish Geotechnical Institute, Copenhagen.

[15] Teodoru, I.B., Musat, V. and Vrabie, M. (2006) A Finite Element Study of the Bending Behavior of Beams Resting on Two-Parameter Elastic Foundation. Bulletin of the Polytechnic Institute of Iasi, 65, 7-20.

[16] Dinev, D. (2012) Analytical Solution of Beam on Elastic Foundation by Singularity Function. Engineering Mechanics, 19, 381-392.

[17] Teodoru, I.B. (2009) Beams on Elastic Foundations-The Simplified Continuum Approach. Bulletin of the Polytechnic Institute of Iasi, 65, 37-46.

[18] Sall, O.A., Fall, M., Berthaud, Y. and Ba, M. (2013) Influence of the Elastic Modulus of the Soil and Concrete Foundation on the Displacement of a Mat Foundation. Open Journal Civil Engineering, 3, 228-233. https://doi.org/10.4236/ojce.2013.34027

[19] Vallabhan, C. and Das, Y. (1988) Parametric Study Beams on Elastic Foundations. Journal of Engineering Mechanics, 114, 2072-2082. https://doi.org/10.1061/(ASCE)0733-9399(1988)114:12(2072)

[20] Eurocode 7 (2004) Geotechnical Design-Part 1: General Rules. European Committee for Standardization.

[21] "Radimpex Software”, Tower, 2012, Beograd.

[22] Djurić, M. (1970) Static Construction. Naučna Knjiga, Beograd.

[23] Schmertmann, J.H., Hartman, J.P. and Brown, P.R. (1978) Improved Strain Influence Factor Diagrams. Journal of the Geotechnical Engineering Division, 104, 1131-1135. 